\title{
Hierarchical Microchannel Carbons Derived from Biological Phloem Tissues as High-Performance Anode for Lithium-Ion Batteries
}

\author{
Yunlong Liao", Jiahua Hu ${ }^{1,2}$, Zhuang Sun ${ }^{3,}$, Wei Zhang, , Xiaomeng Zhou ${ }^{2}$, Haijun Zhang ${ }^{2, ~ * ~}$ \\ ${ }^{1}$ School of Safety Science and Engineering, Civil Aviation University of China, Tianjin, China \\ ${ }^{2}$ Key Laboratory of Civil Aviation Thermal Hazards Prevention and Emergency Response, Civil Aviation University of China, Tianjin, China \\ ${ }^{3}$ The State Key Lab of High Performance Ceramics and Superfine Microstructure, Shanghai Institute of Ceramics, Chinese Academy of \\ Sciences, Shanghai, P. R. China
}

\section{Email address:}

yunlongliao@gmail.com (Yunlong Liao),jiahua_hu@126.com (Jiahua Hu), zwizhy@126.com (Wei Zhang),

zhuangsun@mail.sic.ac.cn (Zhuang Sun), zhouxm@nankai.edu.cn (Xiaomeng Zhou), hjzhang_ahu@163.com (Haijun Zhang)

${ }^{*}$ Corresponding author

\section{To cite this article:}

Yunlong Liao, Jiahua Hu, Zhuang Sun, Wei Zhang, Xiaomeng Zhou, Haijun Zhang. Hierarchical Microchannel Carbons Derived from Biological Phloem Tissues as High-Performance Anode for Lithium-Ion Batteries. Journal of Electrical and Electronic Engineering. Vol. 9, No. 5, 2021, pp. 153-160. doi: 10.11648/j.jeee.20210905.12

Received: June 29, 2021; Accepted: July 15, 2021; Published: September 15, 2021

\begin{abstract}
With the upgrading of consumption, the existing carbon-based anode materials are facing the major challenges of high preparation cost and low initial Coulomb efficiency. The fast-growing and developed sieve tube network is an inspiration to transform cattail phloem tissue (CPT) into a high-performance carbon-based anode for lithium-ion battery. In this study, porous carbon materials from CPT with abundant microchannel and nanochannel were prepared by a top-down strategy combined with an indispensable passivation process. The sidewall and end of the sieve tube are fully covered by a large number of pore structures and various supporting cells, thus ensuring the stiffness and tensile strength of phloem tissue. And benefiting from the neoteric hierarchical porous structure without $\mathrm{Li}^{+}$trapping sites, the cells with CPT anode showed high electrochemical performance. For the passivated CPT electrode, the reversible capacity increased to $321.6 \mathrm{mAh} / \mathrm{g}$, and the initial Coulomb efficiency was 1.47 times higher than that of the passivated CPT electrode. The CPT exhibits excellent rate performance under high current, which indicates that the abundant pore structure on the surface of the sieve tube is an effective measure to improve ion diffusion. Besides, the generation mechanism of high-performance CPT is analyzed through microstructure characterization. The improvement of electrochemical performance of CPT in this work has provided a clear strategy for the application of resource-rich natural biomass to electrochemical products.
\end{abstract}

Keywords: Phloem Tissue Carbon, Porous Anode, Lithium-Ion Battery, Biomass Carbon

\section{Introduction}

The expansion of social demand for portable electrical equipment, low-carbon vehicles, and electric grids has boosted the new energy economy, driven by cheap, sustainable, and safe energy supply. As the most practical secondary energy storage product, lithium-ion batteries (LIBs) have developed rapidly and been widely applied due to their excellent energy storage efficiency, no memory effect, and less consumption [1,2]. It is a fundamental scientific and technical challenge to design and prepare better electrode materials to further meet the increasingly growing demand for high-power LIBs [3].

Anode material greatly influences the comprehensive performance of the cell. The technically available anodes for LIBs are mainly insertion-type graphite $[4,5]$ and conversion reaction-type silicon [6,7]. Although graphite has been widely used in LIBs anode electrode materials due to its abundant natural resources and excellent comprehensive electrochemical properties, the theoretical capacity of 372 $\mathrm{mAh} / \mathrm{g}$, and prone to collapse after a long cycle hinder its application. Conversion reaction-type anodes are limited in commercial applications by their severe volume expansion. 
However, with the gradual popularization of electric vehicles and increasing demand for renewable resources, huge availability, rapid regeneration, and high-performance electrodes, the design and standardized manufacture of new anode materials has become a top priority.

Hard carbon is an excellent anode material for high-power batteries because of its interlaced layered structure, enabling $\mathrm{Li}^{+}$to intercalate and release rapidly, better low-temperature performance, and higher reversible specific capacity. Recently, natural biomass-derived carbon has attracted tremendous attention due to its high adaptability for use as an anode material $[8,9]$. Elements such as carbon, sulfur, and nitrogen are the material basis of biomass. Accordingly, the inherent component structure of biomass can serve as templates to fabricate electrodes with special geometries [10]. More importantly, the unique hierarchical structure and properties of biomass carbon are compatible with the related reactions during lithium-ion migration [11]. Therefore, scientists worldwide have focused on preparing biomass porous carbon materials through environmentally friendly methods with great enthusiasm $[12,13]$.

The raw materials and synthesis strategies of biomass-derived carbon have significant effects on its morphological characteristics, physical properties, and chemical compositions, which are related to energy conversion/storage performance. Much renewable biomass has been used as precursors of carbon-containing materials for LIBs, such as bamboo [14], olive [15], corn stalk core [16], wheat straw [17], soybean residues [18], rice husks [19], woodchips [20], and shrimp shells [21]. For example, Xiao and his coworker [22] reported that the porous nitrogen-rich $(5.13 \%)$ carbon materials were prepared from wheat straw, and the ultra-high rate performance was nearly $344 \mathrm{mAg} / \mathrm{g}$ at $18.5 \mathrm{~A} / \mathrm{g}$. Ru et al. [18] modified the structure of bean dregs derived carbon by graphitization and chemical activation. A specific capacity of $396 \mathrm{mAh} / \mathrm{g}$ was obtained after 100 cycles at 0.1C. Yu et al. [19] prepared activated carbon with layered porous structure from rice husk raw material by a simple, robust alkali activation method. The tested reversible capacity was $448 \mathrm{mAh} / \mathrm{g}$ after 100 cycles at $0.2 \mathrm{C}$, but the rate performance is low due to the limited number of micropores. However, their vast availability and high-performance electrochemical property were unsatisfactory.

Cattail is a fast-growing vascular plant with superior productivity, which is considered a biomass crop particularly suitable for wetlands. The Cattail leaves, especially leaf bark, are rich in the phloem tissue and have highly arranged sieve tubes necessary for the metabolism of salt, plant juice, and organic compounds. Phloem tissue is an important link channel leading to the distal ends in the vascular network of mature plants. Based on the natural properties of Cattail leaves, we prepared porous hard carbon by a simple carbonization and passivation method. The electrochemical properties and structural characteristics of phloem tissue carbon of Cattail (CPT) as an anode material for LIBs were studied for the first time. CPT has large multistage pores for high $\mathrm{Li}^{+}$storage and has hierarchical pores for a fast $\mathrm{Li}^{+}$diffusion rate. What's more, such low-cost and environment-friendly biomass carbon has an excellent value for large-scale commercial applications.

\section{Experimental Section}

\subsection{Preparation of CPT Materials}

CPT samples were obtained from the Cattail leaves epidermis, rinsed five or more times with deionized water and ethanol, sliced, and dried at a constant temperature of $120^{\circ} \mathrm{C}$ in a vacuum environment. The mesophyll tissue was peeled from the dried leaf pieces with a scraper blade, and the epidermis was cleaned with ultrasound in ethanol for 120 minutes. The leaf epidermis was heated in a tube furnace under argon to $1300^{\circ} \mathrm{C}$ for four hours at $5^{\circ} \mathrm{C} / \mathrm{min}$. Subsequently, the carbonized leaf bark was placed in $5 \mathrm{M}$ $\mathrm{KOH}$ and $3 \mathrm{M} \mathrm{HCl}$ for $720 \mathrm{~min}$ at $60^{\circ} \mathrm{C}$, respectively, to gradually reduce impurities. After that, the purified substance was rinsed with deionized water and dried continuously for more than 600 min. Finally, the obtained samples were heated in a tube furnace at $800^{\circ} \mathrm{C}$ for $180 \mathrm{~min}$ in argon. CPT was obtained after grinding for $15 \mathrm{~min}$.

\subsection{Materials Characterization}

A field emission scanning electron microscope (FE-SEM, SU8220) was used to observe CPT and EDS mapping analysis The TEM, HRTEM, and SAED images were recorded by a transmission electron microscope (JEOL JEM-2010F). At the end of the cycling experiments, coin cells were disassembled in argon, the cathode part was rinsed with 1, 2-dimethoxyethane (anhydrous, Sigma), and dried for 120 min. The CPT sample was tested by X-ray diffraction (XRD) measurement (BRUKER AXS GMBH, D8ADVANCE). Nitrogen adsorption and desorption measurement were characterized using Autosorb iQ equipment, Brunauer calculated the surface area-Emmett-Teller (BET) method, and Raman spectra were derived with a DXR Raman microscope. A spectrometer (Kratos AXIS Ultra DLD) was used for X-ray photoelectron spectroscopy (XPS) measurement. The obtained samples were synthesized for Fourier transform infrared (FTIR) analysis on a Thermo Fisher Scientific instrument from 4000 to $500 \mathrm{~cm}^{-1}$.

\subsection{Electrochemical Analysis}

The anode electrode was synthesized by coating the slurry of CPT powder $(80 \mathrm{wt} \%)$, Super $\mathrm{P}(10 \mathrm{wt} \%)$ as the conductive agent, and polyvinylidene fluoride $(10 \mathrm{wt} \%)$ as the binder slurry dissolved in N-methyl pyrrolidinone (NMP) on copper foil and drying at $120^{\circ} \mathrm{C}$. The average mass of the active substance is $0.7 \mathrm{mg}$. The electrochemical performance of CPT as anode electrode was tested in CR2025 coin-cell with lithium metal as a counter electrode, a polypropylene microporous film as the separator, and a mixture of 1 M LiPF6 in ethylene carbonate (EC), ethyl methyl carbonate (EMC), and dimethyl carbonate (DMC) (1: 1: 1, v/v/v) as the electrolyte. All cells used Celgard polypropylene as a separator and assembled in a glove box in argon. Cyclic 
voltammetry (CV) test was carried out at the Bio-logic VSP workstation. The galvanostatic charge/discharge cycling test was carried out in a battery test system (Land CT2001B), and the potential range was 0.01 to 3.0 (vs. $\mathrm{Li}^{+} / \mathrm{Li}$ ).

\section{Results and Discussion}
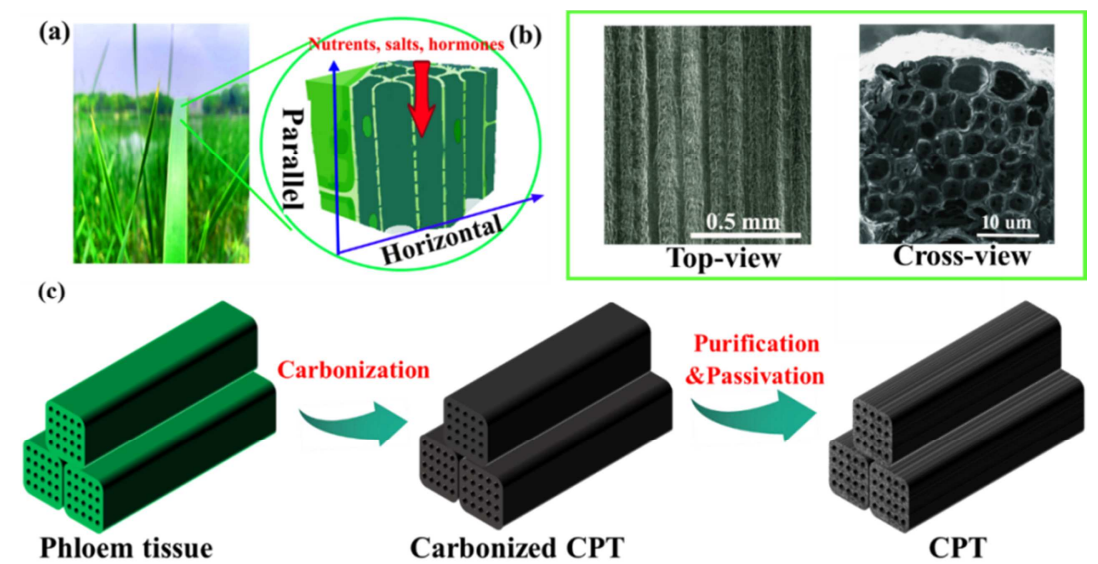

Figure 1. CPT preparation process. (a) Cattail leaves and their structural schematic diagram. (b) SEM of top and cross-sectional views of CPT. (c) CPT synthesis process.
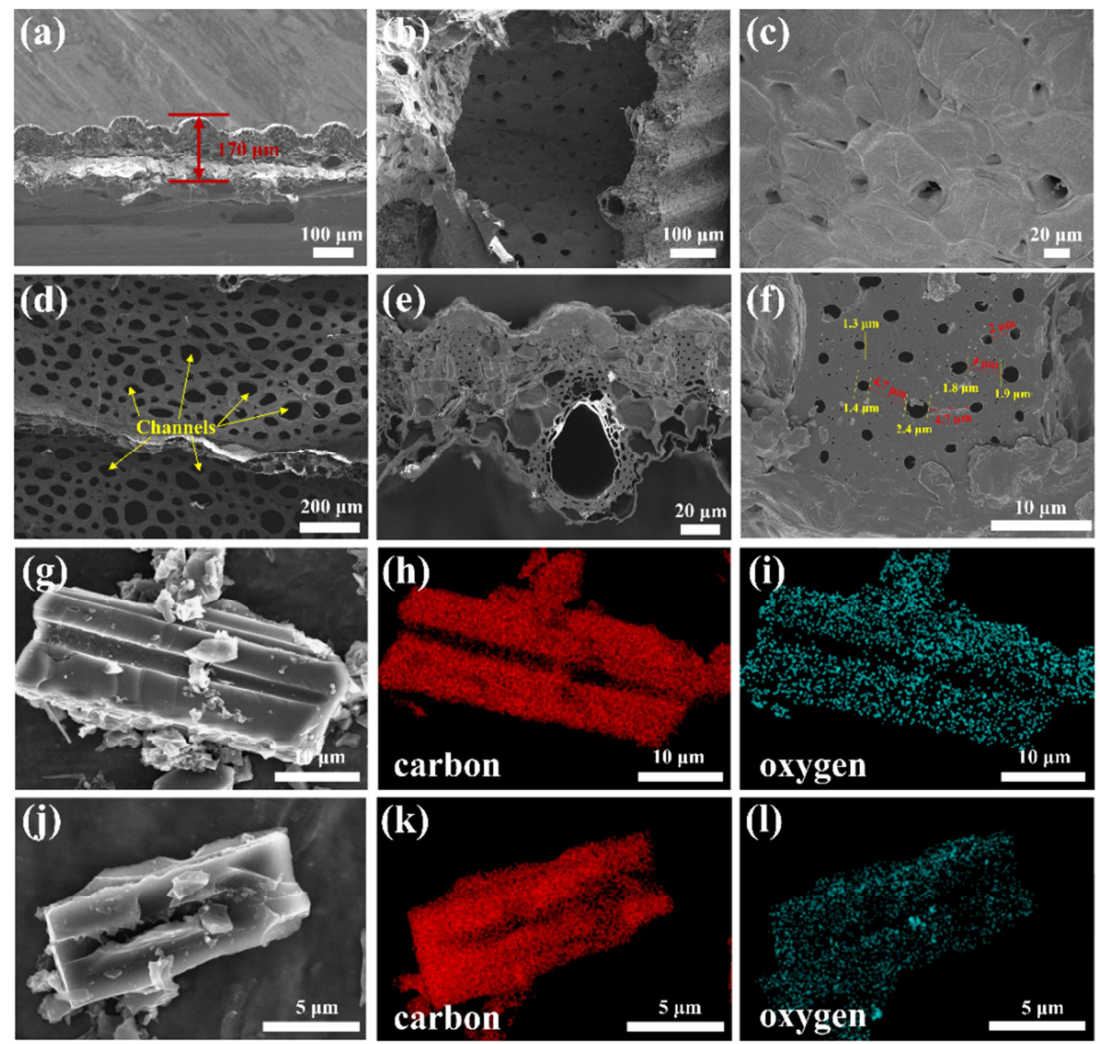

Figure 2. The morphology of CPT. SEM images of (a) Cross-section image of a treated Cattail leaf, (b-c) the magnified images of phloem tissues in Cattail leaf before carbonization, (d-f) the magnified images of CPT sample. ( $g$-l) SEM and elemental mapping images of CPT samples before and after passivation.

The phloem tissues in Cattail leaf have a unique structure composed of sieve tubes supporting nutrient transfer during photosynthesis. The sidewalls and ends of these sieve tubes are covered with rich pore structures and various supporting cells, effectively increasing the bast tissue's rigidity and tensile strength. These ordered and structurally stable microchannels can well transport ions or soluble organic compounds. Therefore, it is highly advantageous to convert phloem tissues from Cattail leaves directly to electrode material because of its novel geometrical structure, rapid processing, and cost-effective pristine biological quality. Figure 1a shows a schematic diagram of the leaf's structure and a wild Cattail's phloem tissues. After removing the mesophyll in Cattail leaves, the epidermal parts are rich in phloem tissue structure with one-dimensional micron-scale carbon fiber material microchannels, as shown in Figure $1 \mathrm{~b}$. 
Compared to the ease of fabrication of CPT from pyrolysis of Cattail leaves, it would be a grand challenge to chemically synthesize such a well-ordered microlayer structure on a large scale from molecular precursors, which typically requires unique structural models, strict reaction conditions, and high costs. In Figure 1c, the method shown from left to right to directly convert the original CPT preparation from Cattail leaves involving carbonization, purification, and passivation.

The SEM images and elemental mapping images of CPT are shown in Figure 2. Although Cattail leaves were treated with high-temperature carbonization, impurities removing, and passivation process, the anisotropic structure was still intact with well-arranged microchannels parallel to the blades. Figure $2 \mathrm{a}$ is the SEM image of the leaf cross-section with a thickness of $170 \mu \mathrm{m}$. Figure 2b-c shows obvious microchannels and fiber structures, which are composed of cellulose molecules. As shown in Figure 2d-e, the Cattail leaf's fiber structure and microchannels are well preserved.

(a)
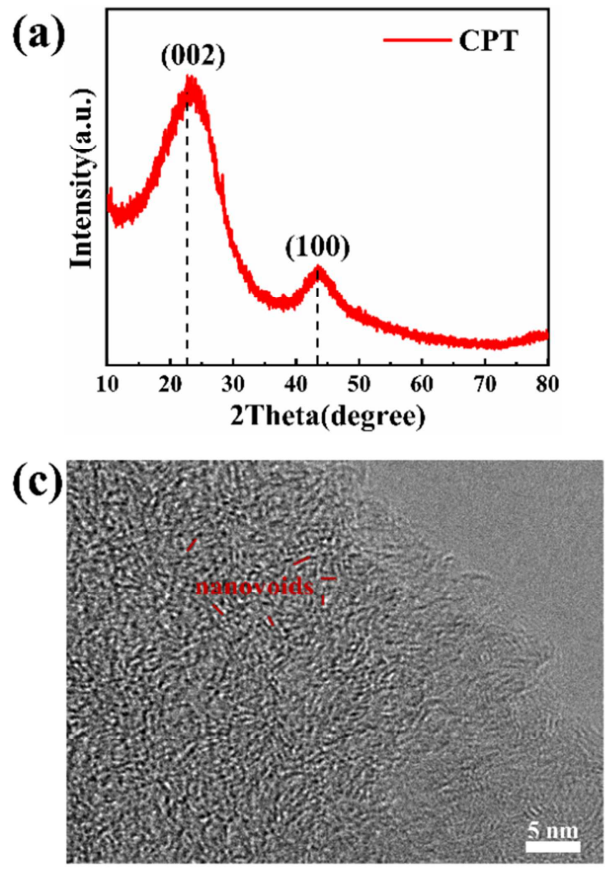

Porous structures were fabricated with $\mathrm{KOH}$ at $60^{\circ} \mathrm{C}$, and impurities were stripped by $\mathrm{HCl}$ rinsing. In Figure $2 \mathrm{f}$, microchannels on the sieve tubes are arranged sequentially with a diameter from 1.0 to $2.4 \mu \mathrm{m}$. The average thickness of the tube wall is about $4.0 \mu \mathrm{m}$, which can ensure the sieve tubes structure's mechanical strength. The micropores in the wall are randomly distributed. Related contents of the microporous structure are discussed in more detail in Figure 4. The rich microchannels are beneficial to the migration of $\mathrm{Li}^{+}$and the fabric's stability, which may improve the electrochemical performance of CPT. As shown in Figures $2 \mathrm{~g}$ and $2 \mathrm{j}$, the ground CPT powders have a one-dimensional tubular structure before and after the passivation treatment. In addition, the energy dispersive spectroscopy results mainly include carbon and oxygen. However, the oxygen element reduced from 6.8 to $1.2 \%$ after the passivation processing, indicating that a large number of oxygen-containing functional groups disappeared.

(b)

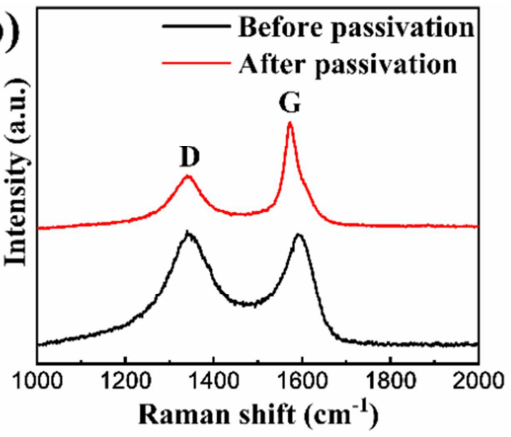

(d)

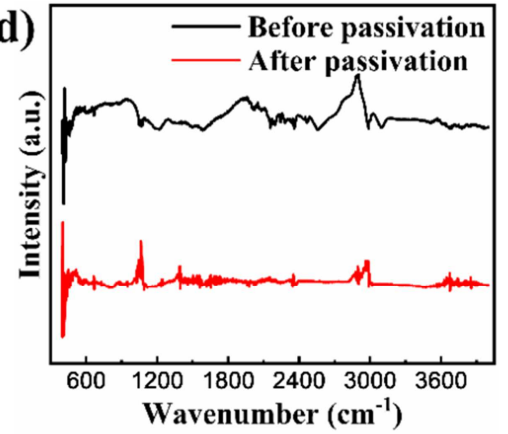

Figure 3. (a) XRD, (b) Raman spectra, (c) TEM, and (d) FTIR of CPT.

The graphitization degree of CPT was characterized by XRD and Raman spectroscopy. In Figure 3a, two broad diffraction peaks appear at $22^{\circ}$ and $43^{\circ}$ in XRD, corresponding to (002) and (100) crystal planes. The height at (002) characterizes the degree of parallel stacking of graphene sheets, while the peak at (100) is influenced by the honeycomb structure containing $\mathrm{sp}^{2}$ hybrid carbon [23]. Analysis of the (002) reflection gives the average interlayer spacing $d(002)$ (calculated by the Bragg equation) is $0.395 \mathrm{~nm}$. Compared to the standard phase analysis data of graphite, the peak (002) position in Figure 3 a moves to a lower position, indicating the nature of hard carbon [18].

In the Raman spectrum, the $G$ band characterizes the graphitized $\mathrm{sp}^{2}$ hybrid carbon, and the $\mathrm{D}$ band characterizes the $\mathrm{sp}^{3}$ hybrid carbon with the disordered state such as edges, disordered carbon, and other defects. Figure $3 b$ shows the result of Raman spectroscopy before and after CPT passivation. Two characteristic peaks of unpassivated CPT, D peak and $\mathrm{G}$ peak, appeared at 1340 and $1589 \mathrm{~cm}^{-1}$. And the D peak and $\mathrm{G}$ peak of passivated CPT appeared at 1340 and $1573 \mathrm{~cm}^{-1}$ respectively. The $\mathrm{I}_{\mathrm{D}} / \mathrm{I}_{\mathrm{G}}$ of $\mathrm{D}$ peak and $\mathrm{G}$ peak is typically used to describe the disorder degree of the $\mathrm{sp}^{2}$ domains. The Raman fitting result of $\mathrm{I}_{\mathrm{D}} / \mathrm{I}_{\mathrm{G}}$ of unpassivated CPT is 1.03 , while the value of $\mathrm{I}_{\mathrm{D}} / \mathrm{I}_{\mathrm{G}}$ of passivated CPT is 0.75 . This indicates that the CPT obtained after passivation is mainly composed of well-crystallized graphitic carbon [24, 25], and the surface defects are obviously less than those of the samples without passivation.

The parallel carbon hexagonal layers surrounded by nano-voids has widely appeared in Figure 3c. The size of 
nanovoids is generally within $1-2 \mathrm{~nm}$, which may be due to local displacement of the carbon layers at high temperatures. Figure $3 \mathrm{~d}$ shows the FTIR spectra of CPT before and after passivation. When running in an air environment, prominent peaks of unpassivated CPT are at 1060, 1886, and $2901 \mathrm{~cm}^{-1}$, respectively,

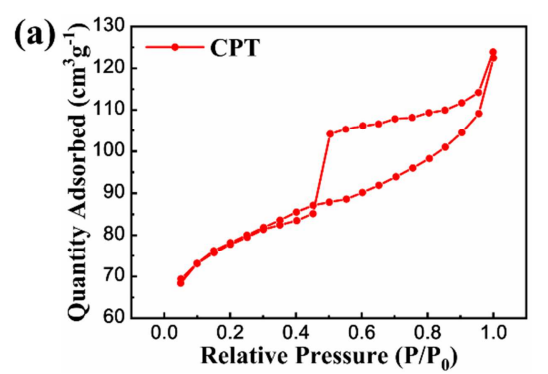

corresponding to $\mathrm{C}-\mathrm{O}, \mathrm{C}=\mathrm{O}$, and $\mathrm{C}-\mathrm{H}$ bonds. However, after passivation treatment, the peaks are tended to be flat, proving that the oxygen-containing groups and $\mathrm{C}-\mathrm{H}$ bonds on the carbon surface are reduced, which is very beneficial to reduce irreversible side reactions in carbon-based anode materials [26].

Figure 4. (a) BET $N_{2}$ adsorption/desorption isotherms and (b) pore size distribution of CPT nanomaterials.

The $\mathrm{N}_{2}$ adsorption-desorption isotherm of the CPT sample is shown in Figure 4a. The nitrogen adsorption isotherm showed that the BET surface area of CPT was $476 \mathrm{~m}^{2} / \mathrm{g}$, leading to a sufficient electrode-electrolyte interface to absorb $\mathrm{Li}^{+}$, promoting specific capacity. The isotherm's adsorption curve is inconsistent with the desorption curve with an obvious hysteresis loop, and the isotherm eventually turns upwards in the region with a higher $\mathrm{P} / \mathrm{P}_{0}$ value. Therefore, the curve belongs to the IV-type adsorption isotherm, which indicates many mesopores are present in the CPT samples. Monolayers mainly occur in the low specific pressure range. As shown in Figure 4a, a few points in the low relative pressure area and the curve do not rise sharply, indicating that the number of micropores in the sample is relatively high. When the $\mathrm{P} / \mathrm{P}_{0}$ value is close to 1.0 , the capillary condensation is forced by the increase in pressure, and the slope of the curve increases greatly. The larger the aperture of the mesopore, the higher the pressure of the capillary condensation. It is worth noting that the isotherm's curve transition position is relatively lagging, indicating that the mesopore diameter in the CPT

(a)

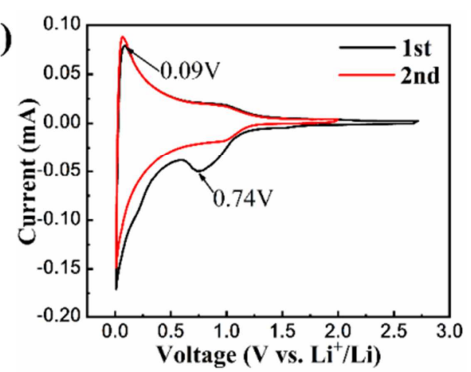

(c)

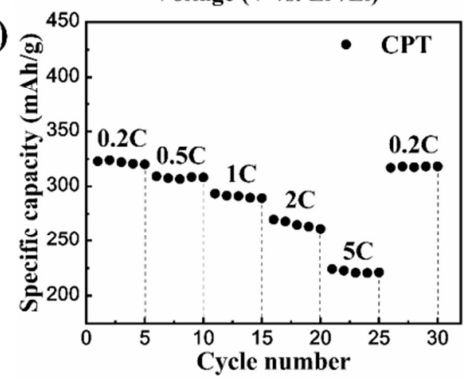

sample is relatively large. Typically, the single-layer adsorption in the low specific pressure stage is reversible. The desorption curve containing very steep desorption branches belongs to the $\mathrm{H}_{2}$-type hysteresis loop, meaning relatively narrow ink bottle-shaped mesopores in the CPT samples and a more complex pore structure.

The pore size distribution data of CPT is shown in Figure $4 \mathrm{~b}$. The pore size is densely distributed within $1.0-12.0 \mathrm{~nm}$, and the peak positions are about $\sim 1.3, \sim 3.0$, and $126.0 \mathrm{~nm}$, respectively. The presence of micropores $(\sim 1.3 \mathrm{~nm})$ and mesopores $(\sim 3.0 \mathrm{~nm})$ contribute to enhanced capillary action in CPT and effectively promote electrolyte penetration. Hence, it can be well illustrated that the natural macrochannel and hierarchical pores in the CPT structure improve lithium-ions transport capacity. Among them, mesopores and macropores can increase the exposed area of the anode, while micropores can effectively enhance electrolytes' permeability. Lithium-ions can penetrate deeper areas more quickly. These measured pore size distribution results are slightly different from other literature [24], which may be from the CPT's unique feature.

(b)
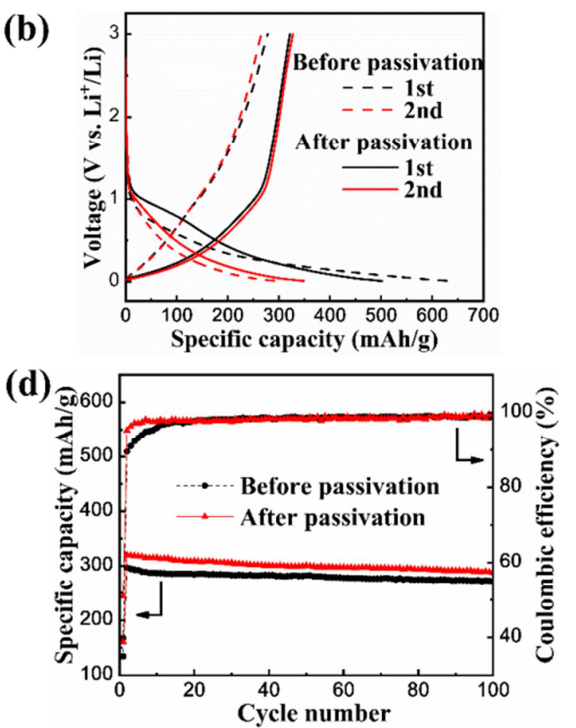

Figure 5. Electrochemical characterization of CPT electrode-based LIBs. (a) CV curve and (b) charge-discharge curve; (c) rate capability at different current strengths; (d) cyclic performance. 
The prepared carbon nanomaterials were assembled into coin cells. Figure 5a displayed the $\mathrm{CV}$ curve of CPT at $1^{\text {st }}$ and $2^{\mathrm{n}} \mathrm{d}$ cycles in the lithium-ion electrolyte at a scanning rate of $0.1 \mathrm{mV} / \mathrm{s}$. In the $1^{\text {st }}$ cycle, shape curves reflected the reaction kinetics of $\mathrm{Li}^{+}$insertion and delithiation. During the first cycle of lithium insertion, two prominent cathode peaks appeared at $\sim 0 \mathrm{~V}$ and $\sim 0.74 \mathrm{~V}$. The cathode peak at $\sim 0 \mathrm{~V}$ is related to the transformation of $\mathrm{Li}^{+}$insertion into nanochannels and microchannels. The wider cathodic peak at $0.74 \mathrm{~V}$ is caused by the rapid formation of solid electrolyte interphase (SEI) and irreversible side reactions caused by electrolyte decomposition. However, this peak disappears in the subsequent cycles, indicating a larger initial irreversible capacity after the first cycle. In Figure 5b, the reversible capacity of the unpassivated CPT in the 1 st cycle was 278.1 $\mathrm{mAh} / \mathrm{g}$ with an initial Coulombic efficiency of $43.4 \%$, while the reversible capacity in the $2^{\text {nd }}$ cycle reduced to 265.3 $\mathrm{mAh} / \mathrm{g}$ with increased Coulombic efficiency of $88.6 \%$. However, for the passivated CPT electrode, the reversible capacity increased up to $321.6 \mathrm{mAh} / \mathrm{g}$ with improved initial Coulombic efficiency of $64.0 \%$, which is 1.47 times higher than that of the unpassivated CPT electrode. And the reversible capacity increased to $327.9 \mathrm{mAh} / \mathrm{g}$ and higher Coulombic efficiency of $94.0 \%$ in the $2^{\text {nd }}$ cycle. Results show that non-passivated CPT presents larger lithiation capacity but lower initial Coulombic efficiency due to the existence of oxygen groups and residual $\mathrm{H}$ atoms on the surface of CPT. However, it is effective to increase the reversible capacity and initial Coulombic efficiency of CPT anode through Ar high-temperature passivation.

The rate performance test of the CPT electrode is displayed in Figure 5c. At low current intensities, the CPT electrode revealed a relatively high specific capacity of $326.1 \mathrm{mAh} / \mathrm{g}$ in the first five cycles. In the subsequent cycles, the individual capacity showed a decline, which may be due to the increase in current intensity leading to more severe polarization. Although

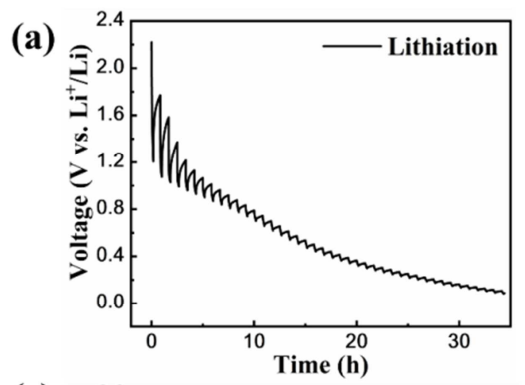

(c)

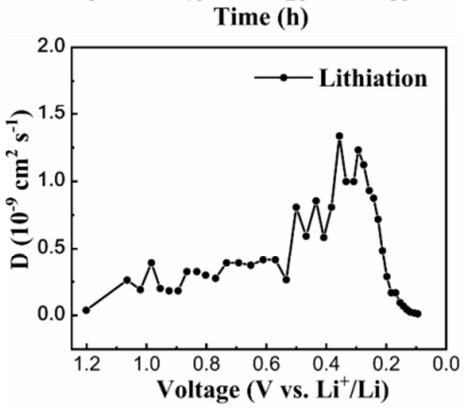

the CPT electrode's capacity is reduced at $5 \mathrm{C}$, which can still provide a capacity exceeding $224.4 \mathrm{mAh} / \mathrm{g}$ showing good capacity retention. When the current reaches $0.2 \mathrm{C}$ again, it can still maintain a capacity exceeding $318.3 \mathrm{mAh} / \mathrm{g}$, which indicates that the CPT electrode has a relatively high rate capacity and structural stability even at large current intensities. Compared with CNTs with a similar tubular structure [27], CPT shows an excellent rate performance, demonstrating that the porous structure in the sieve tube did improve lithium-ion migration efficiency. Moreover, the CPT electrode also presents better rate performance than other forms of hard carbon such as microspheres, carbon nanoflakes [28]. The enhanced electrical properties of CPT may contribute to its unique geometrical structure of microsieve tube with a fixed diameter and large pore structure, which is beneficial to the stable radial movement of ions and significant reduction of the obstacles encountered in the diffusion process.

Figure $5 \mathrm{~d}$ shows the cycling performance of the CPT electrode before and after Ar high-temperature passivation. The passivated CPT electrode's reversible capacity is 291.8 $\mathrm{mAh} / \mathrm{g}$ after 100 cycles at $0.2 \mathrm{C}$, which is better than 271.9 $\mathrm{mAh} / \mathrm{g}$ when it is not passivated. It is of great significant importance for anode materials in full cell application. The large fluctuation of the capacity retention rate may come from the stable CPT anode structure during the circulation process. The thick tube wall of CPT provides long-cycle stability, and the graded porosity improves the rate performance and specific capacity. Although the initial Coulombic efficiency is relatively low, it quickly increased to about $98.0 \%$ in subsequent cycles, which may be related to the electrolyte and anode interface's stability structure. After comparing with other biomass hard carbon, the CPT electrode prepared in this work showed excellent cycle performance. However, there are still slight differences in various anode materials' electrochemical performance, caused by various preparation methods and material structures.

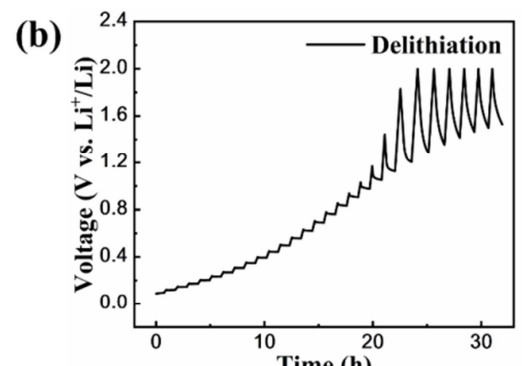

(d)

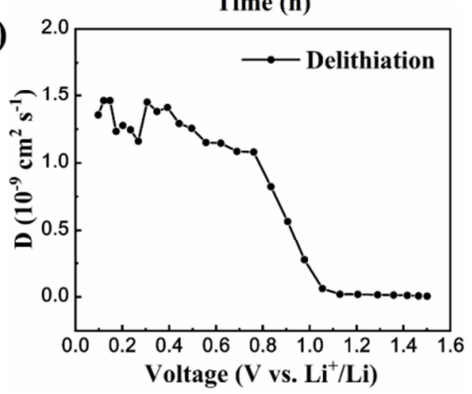

Figure 6. Galvanostatic intermittent titration technique (GITT) results of CPT. Potential profiles for (a) lithiation and (b) delithiation. $i^{+}$diffusion coefficient curves for (c) lithiation and (d) delithiation. 
In order to have a deeper understanding of the rate performance of CPT, the diffusion coefficient of $\mathrm{Li}^{+}$in the CPT electrode was characterized by GITT. Assuming that the overpotential produced by the button cell's electrode material is negligible, according to Fick's second law, the diffusion coefficient of $\mathrm{Li}^{+}\left(D_{\mathrm{Li}}\right)$ is estimated by the following formula. The nomenclature in the formula is shown in Table 1.

$$
D_{L i+}=\frac{4}{\pi \tau}\left(\frac{m_{B}}{M_{B}} \frac{V_{m}}{S}\right)^{2}\left(\frac{\Delta E_{S}}{\Delta E_{t}}\right)^{2}
$$

Figures $6 \mathrm{a}$ and $6 \mathrm{~b}$ show the complete GITT potential profile. In Figure $6 \mathrm{c}$, the order of magnitude of $D_{L i+}$ is $10^{-9} \mathrm{~cm}^{2} / \mathrm{g}$. During the lithiation, the $D_{L i+}$ of CPT generally rises slowly and then drops rapidly. A dense low diffusion coefficient appears before the cut-off potential, explaining how the capacity decreases quickly when charging at high speed in Figure 5c. In Figure 6d, during the delithiation, the $D_{L i+}$ keeps a relatively stable change level in the low-pressure stage, then starts to drop rapidly near $0.8 \mathrm{~V}$, and finally keeps a low level after 1.0 V. Compared with related research results [29, 30], it is found that not only the magnitude of $D_{L i+}$ of our CPT material has obvious advantages, but also there is no obvious dense area with low diffusion coefficient in the process of lithiation and delithiation. This characteristic is related not only to the hierarchical pore but also to the abundant microchannels naturally existing in the phloem of Cattail latifolia.

Table 1. The nomenclature in $D_{L^{+}+}$formula.

\begin{tabular}{ll}
\hline Symbols & Meaning \\
\hline$\tau$ & Duration of the current pulse \\
$m_{B}$ & Active mass \\
$M_{B}$ & Molar mass \\
$V_{m}$ & Molar volume \\
$S$ & Active surface area \\
$\Delta E_{s}$ & Change of the quasi-equilibrium potential \\
$\Delta E_{t}$ & Cell voltage during the current pulse \\
\hline
\end{tabular}

\section{Conclusion}

Highly porous CPT nanomaterials were successfully synthesized from biomass Cattail leaves by a facile top-down strategy. The CPT anode exhibits abundant and hierarchical micro- and nano- channels, which is conducive to the migration and diffusion of $\mathrm{Li}^{+}$. Of note is that the prepared micron sieve tubes after calcination and passivation processes possess a high specific surface but with few irreversible sites to trap $\mathrm{Li}^{+}$, which can effectively expend the reversible storage capacity of the anode. The reversible capacity of the CPT anode is $327.9 \mathrm{mAh} / \mathrm{g}$, which can be used as an effective substitute for graphite. Furthermore, the CPT anode achieves good rate performance. The specific capacity could retain at $224.4 \mathrm{mAh} / \mathrm{g}$ even at a large current density of $1630 \mathrm{~mA} / \mathrm{g}$. The excellent rate performance of CPT electrodes could be explained by the diffusion coefficient analysis of $\mathrm{Li}^{+}$, which can further benefit understanding hard carbon electrodes' rate performance. The abundant porous structure and microchannels in the CPT electrode can reduce the $\mathrm{Li}^{+}$ diffusion distance and optimize the rate performance. More importantly, this research not only contributes to a green and sustainable strategy that natural biomass-driven carbon with hierarchical pores and channels can become a high-efficiency carbon-based anode only after simple treatment but also indicates the possibility of large-scale commercialization of this biomass with abundant sources.

\section{Data Availability Statement}

Some or all data, models, or code generated or used during the study are available from the corresponding author by request.

\section{Conflict of Interest}

All the authors do not have any possible conflicts of interest.

\section{Acknowledgements}

Yunlong Liao acknowledges the financial supported by the Research Startup Fund (2020KYQD05) and Scientific Research Projects of Central University (3122020046). Wei Zhang would like to acknowledge the financial supported by the National Natural Science Foundation of China (61801519).

\section{References}

[1] Wang ZF, Fei PY, Xiong HQ, Qin CL, Zhao WM, Liu XZ (2017) $\mathrm{CoFe}_{2} \mathrm{O}_{4}$ nanoplates synthesized by dealloying method as high performance Li-ion battery anodes. Electrochim Acta 252: 295-305. doi: 10.1016/j.electacta.2017.08.189.

[2] Yu SH, Feng XR, Zhang N, Seok J, Abruna HD (2018) Understanding conversion-type electrodes for lithium rechargeable batteries. Accounts Chem Res 51: 273-281. doi: 10.1021/acs.accounts. 7b00487.

[3] Pistone A, Espro C (2020) Current trends on turning biomass wastes into carbon materials for electrochemical sensing and rechargeable battery applications. Curr Opin Green Sustain Chem 26: 100374. doi: 10.1016/j.cogsc.2020.100374.

[4] Feng XN, Ouyang MG, Liu X, Lu LG, Xia Y, He XM (2018) Thermal runaway mechanism of lithium ion battery for electric vehicles: A review. Energy Storage Mater 10: 246-267. doi: 10.1016/j.ensm.2017.05.013.

[5] Wang JG, Jin DD, Liu HY, et al. (2016) All-manganese-based Li-ion batteries with high rate capability and ultralong cycle life. Nano Energy 22: 524-532. doi: 10.1016/j.nanoen.2016.02.051.

[6] Casimir A, Zhang HG, Ogoke O, Amine JC, Lu J, Wu G (2016) Silicon-based anodes for lithium-ion batteries: effectiveness of materials synthesis and electrode preparation. Nano Energy 27: 359-376. doi: 10.1016/j.nanoen.2016.07.023. 
[7] Ma WQ, Liu XZ, Wang X, et al. (2016) Crystalline Cu-silicide stabilizes the performance of a high capacity Si-based Li-ion battery anode. J Mater Chem A 4: 19140-19146. doi: $10.1039 / \mathrm{c} 6 \mathrm{ta} 08740 \mathrm{j}$.

[8] Bi ZH, Kong QQ, Cao YF, et al. (2019) Biomass-derived porous carbon materials with different dimensions for supercapacitor electrodes: a review. J Mater Chem A 7: 16028-16045. doi: 10.1039/c9ta04436a.

[9] Liu WJ, Jiang H, Yu HQ (2019) Emerging applications of biochar-based materials for energy storage and conversion. Energy Environ Sci 12: 1751-1779. doi: 10.1039/c9ee00206e.

[10] Huang BB, Liu YC, Xie ZL (2021) Two dimensional nanocarbons from biomass and biological molecules: Synthetic strategies and energy related applications. J Energy Chem 54: 795-814. doi: 10.1016/j.jechem.2020.06.033.

[11] Chen Y, Liu HB, Jiang B, Zhao Y, Meng XH, Ma TL (2020) Hierarchical porous architectures derived from low-cost biomass equisetum arvense as a promising anode material for lithium-ion batteries. J Mol Struct 1221: 128794. doi: 10.1016/j.molstruc.2020.128794.

[12] Atchudan R, Edison T, Perumal S, Thirukumaran P, Vinodh R, Lee YR (2019) Green synthesis of nitrogen-doped carbon nanograss for supercapacitors. J Taiwan Inst Chem Eng 102: 475-486. doi: 10.1016/j.jtice.2019.06.020.

[13] Liedel C (2020) Sustainable battery materials from biomass. ChemSusChem 13: 2110-2141. doi: 10.1002/cssc.201903577.

[14] Zhang X, Hu JB, Chen XY, Zhang M, Huang QY, Du XQ, Liu Y, Li XJ (2019) Microtubular carbon fibers derived from bamboo and wood as sustainable anodes for lithium and sodium ion batteries. J Porous Mat 26: 1821-1830. doi: 10.1007/s10934-019-00781-3.

[15] Kumagai S, Abe Y, Saito T, Eguchi T, Tomioka M, Kabir M, Tashima D (2019) Lithium-ion capacitor using rice husk-derived cathode and anode active materials adapted to uncontrolled full-pre-lithiation. J Power Sources 437: 226924. doi: 10.1016/j.jpowsour.2019.226924.

[16] Li Y, Li C, Qi H, Yu KF, Liang C (2018) Mesoporous activated carbon from corn stalk core for lithium ion batteries. Chem Phys 506: 10-16. doi: 10.1016/j.chemphys.2018.03.027.

[17] Zhou XY, Chen F, Bai T, Long B, Liao QC, Ren YP, Yang J (2016) Interconnected highly graphitic carbon nanosheets derived from wheat stalk as high performance anode materials for lithium ion batteries. Green Chem 18: 2078-2088. doi: $10.1039 / \mathrm{c} 5 \mathrm{gc} 02122 \mathrm{~g}$.

[18] Ru HH, Xiang KX, Zhou W, Zhu YR, Zhao XS, Chen H (2016) Bean-dreg-derived carbon materials used as superior anode material for lithium-ion batteries. Electrochim Acta 222: 551-560. doi: 10.1016/j.electacta.2016.10.202.

[19] Yu KF, Li J, Qi H, Liang C (2018) High-capacity activated carbon anode material for lithium-ion batteries prepared from rice husk by a facile method. Diam Relat Mat 86: 139-145. doi: 10.1016/j.diamond.2018.04.019.
[20] Adams RA, Dysart AD, Esparza R, Acuna S, Joshi SR, Cox A, Mulqueen D, Pol VG (2016) Superior lithium-ion storage at room and elevated temperature in an industrial woodchip derived porous carbon. Ind Eng Chem Res 55: 8706-8712. doi: 10.1021/acs.iecr.6b01786.

[21] Mondal AK, Kretschmer K, Zhao YF, Liu H, Fan HB, Wang GX (2017) Naturally nitrogen doped porous carbon derived from waste shrimp shells for high-performance lithium ion batteries and supercapacitors. Microporous Mesoporous Mat 246: 72-80. doi: 10.1016/j.micromeso.2017.03.019.

[22] Chen L, Zhang YZ, Lin CH, Yang W, Meng Y, Guo Y, Li ML, Xiao D (2014) Hierarchically porous nitrogen-rich carbon derived from wheat straw as an ultra-high-rate anode for lithium ion batteries. J Mater Chem A 2: 9684-9690. doi: 10.1039/c4ta00501e.

[23] Yan P, Ai FR, Cao CL, Luo ZM (2019) Hierarchically porous carbon derived from wheat straw for high rate lithium ion battery anodes. J Mater Sci-Mater Electron 30: 14120-14129. doi: 10.1007/s10854-019-01778-z.

[24] Sun Z, Zhang YC, Sun B, Yang CS, Zhang T (2020) Micro versus nanochannels: carbon micro-sieve tubes from biological phloem tissues for lithium-oxygen batteries. Green Chem 22: 388-396. doi: $10.1039 / \mathrm{c} 9 \mathrm{gc} 03284 \mathrm{c}$.

[25] Sekar S, Lee Y, Kim DY, Lee S (2019) Substantial LIB anode performance of graphitic carbon nanoflakes derived from biomass green-tea waste. Nanomaterials 9: 871. doi: 10.3390/nano9060871.

[26] Sun D, Luo B, Wang HY, Tang YG, Ji XB, Wang LZ (2019) Engineering the trap effect of residual oxygen atoms and defects in hard carbon anode towards high initial coulombic efficiency. Nano Energy 64: 103937. doi: 10.1016/j.nanoen.2019.103937.

[27] Aslam MK, Shah SSA, Javed MS, Li S, Hussain S, Hu BB, Khan NA, Chen CG (2019) FeCo- $\mathrm{N}_{\mathrm{x}}$ encapsulated in 3D interconnected $\mathrm{N}$-doped carbon nanotubes for ultra-high performance lithium-ion batteries and flexible solid-state symmetric supercapacitors. J Electroanal Chem 855: 113615. doi: 10.1016/j.jelechem.2019.113615.

[28] Zhang XD, Bi ZY, Xu GG, Li CG, He W, Zhu JF (2019) Binary superlattice ceramic membrane-coated soft carbon/hard carbon microspheres for high energy mixed-ion batteries. J Power Sources 438: 226980. doi: 10.1016/j.jpowsour.2019.226980.

[29] Li H, Wang YH, Huang JX, Zhang YY, Zhao JB (2017) Microwave-assisted synthesis of CuS/graphene composite for enhanced lithium storage properties. Electrochim Acta 225: 443-451. doi: 10.1016/j.electacta.2016.12.117.

[30] Wang YH, Zhang YY, Li H, Peng YY, Li JY, Wang J, Hwang BJ, Zhao JB (2018) Realizing high reversible capacity: 3D intertwined CNTs inherently conductive network for $\mathrm{CuS}$ as an anode for lithium ion batteries. Chem Eng J 332: 49-56. doi: 10.1016/j.cej.2017.09.070 